Short Review

\title{
Bio-Based Substances from the Compost of Bio-Waste for Decontamination of Waste Water
}

\section{Razieh Sadraei *}

Faculty of Science and Engineering, Universiy of Wolverhampton, Wulfruna Street, Wolverhampton, United Kingdom; E-Mail: r.sadraei@wlv.ac.uk

* Correspondence: Razieh Sadraei; E-Mail: r.sadraei@wlv.ac.uk

Academic Editor: Consuelo Fritz

Special Issue: Bio-based Materials: Smart and Packaging Applications

Recent Progress in Materials

2020, volume 2, issue 3

doi:10.21926/rpm.2003017
Received: April 25, 2020

Accepted: June 22, 2020

Published: July 01, 2020

\begin{abstract}
A literature survey shows that the valorization of urban and/or agricultural biowastes into chemicals has caught the attention of experts and is gradually becoming quite an important issue. This review presents the application of the Bio-Based Substances (BBS) isolated from the compost of bio-wastes from urban gardening and park trimming residues. The non-cost BBS has been well studied in the literature. BBS are biological macromolecules with a complex lignin-derived structure containing several functional groups, viz., the acid and basic functional groups. These functional groups are bonded to aromatic and aliphatic chains. BBS are mainly acidic in nature, and therefore it is possible to employ them for the surface functionalization of specific inorganic oxides to produce new hybrid materials having a different surface charge. The surface character (surface charge) of new hybrid materials has been modified and developed through an easy and green way for the removal of pollutants from waste water.
\end{abstract}

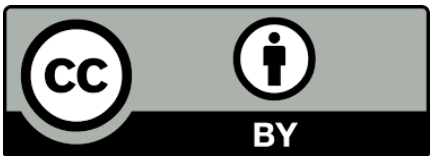

(C) 2020 by the author. This is an open access article distributed under the conditions of the Creative Commons by Attribution License, which permits unrestricted use, distribution, and reproduction in any medium or format, provided the original work is correctly cited. 


\section{Keywords}

Bio-based substances; surface functionalization; removal of pollutant; water treatment; waste water treatment; green chemistry

\section{Introduction}

The literature review indicates that the transformation of agricultural and urban bio-wastes into chemicals is gradually becoming a hot topic for research. Due to the cost effectiveness, scientists work with materials obtained from bio wastes. These economically viable products, obtained by green methods, are industrially valuable. Water soluble Bio-Based Substances (BBS) extracted from bio-waste compost from gardening, urban food, and park trimming residues have found their use in the chemical and environmental industry, e.g., in the fields of detergent manufacture, textile industry, and photodegradation. They have also been used as binders in the synthesis of porous monolithic materials and functionalization of oxides to produce hybrid materials[1-6]. BBS has a potential application as a cost-effective source of valuable renewable bio-based materials in the chemical and consumer market. Increased production due to urbanized population is concentrated in municipal areas where waste is collected. These are a rich source of bio-organic matter. Depending on the waste management, it is possible to meet up to 50 percent of consumer needs. The prospect of a flourishing bio-based economy is presented in Figure 1. The biological nature of the BBS source is a major hindrance in the path of meeting the desirable commercial expectations. This might become a critical issue if it does not allow the supply of reproducible products to users [7]. The functional groups present in BBS are depicted in Scheme 1.

Montoneri and co-workers reported the properties and the chemical composition of products isolated from bio-waste collected from densely populated urban areas [7]. The results indicate that BBS are biological macromolecules with a complex lignin-derived structure. These contain various acidic and basic functional groups linked to aromatic rings and aliphatic chains $[10,11]$. In fact, BBS contains several aromatic rings as well as long aliphatic chains connected to numerous organic functional groups like carboxyl, carbonyl, phenolic, hydroxyl, ester, ether, amide, and amine groups. However, BBS are similar in nature to anionic surfactants. Many anionic surfactants have been applied in various areas like the textile industry, detergents and have been used as binder and templates for monolithic and ceramics products [12-15]. These have also found applications in agriculture. BBS were initially thought to exhibit chemical properties similar to humic substrates; however, they represent a new version of the molecular characteristics of natural organic matter deriving from humification processes occurring either in soil, sediment or recycled biomasses. Currently, it is widely acknowledged that natural organic matter and humic materials are not formed of biopolymers. These are a result of the self-assembled supra-molecular association of relatively small heterogeneous molecules derived from the selective degradation of plant residues and animal tissues, integrated by the incorporation of microbial byproducts. This has made the humic like molecules highly reactive in soil and water treatment processes $[16,17]$. 


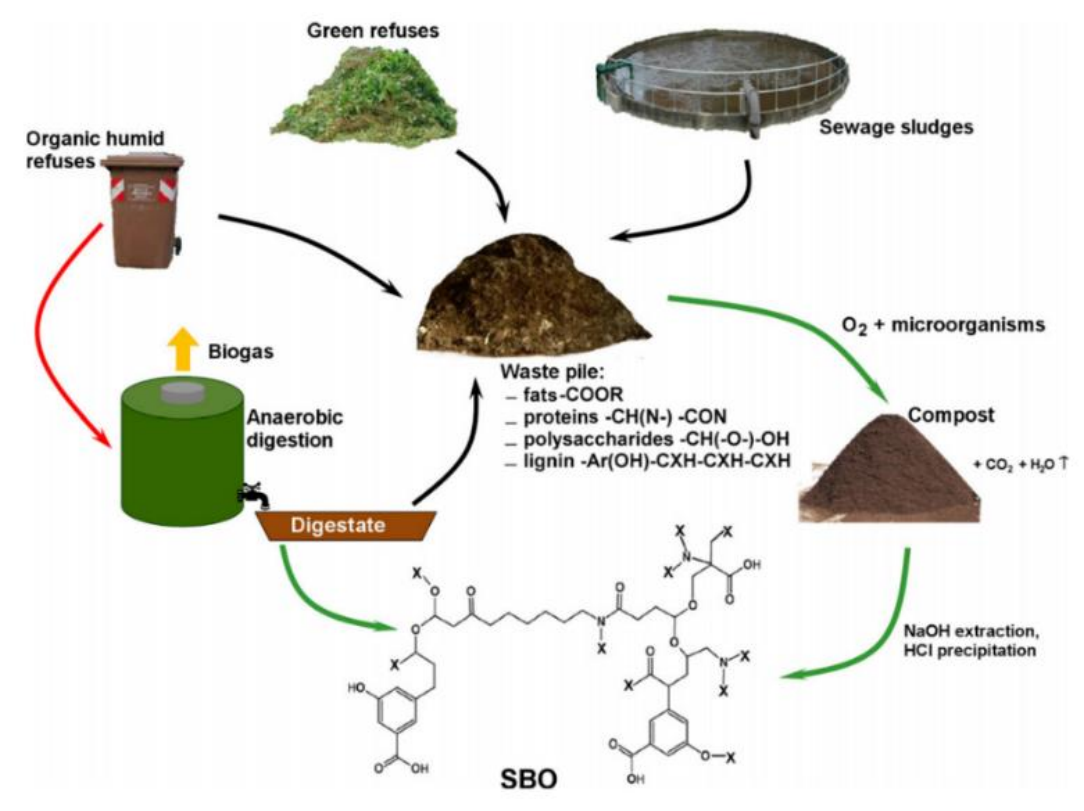

Figure 1 Steps of the main sourcing process and the proposed molecular fragment for BBS. $\mathrm{R}=$ alkyl, $\mathrm{X}=\mathrm{H}$ or $\mathrm{C}, \mathrm{N}, \mathrm{O}$ atoms of other molecular fragments [8].

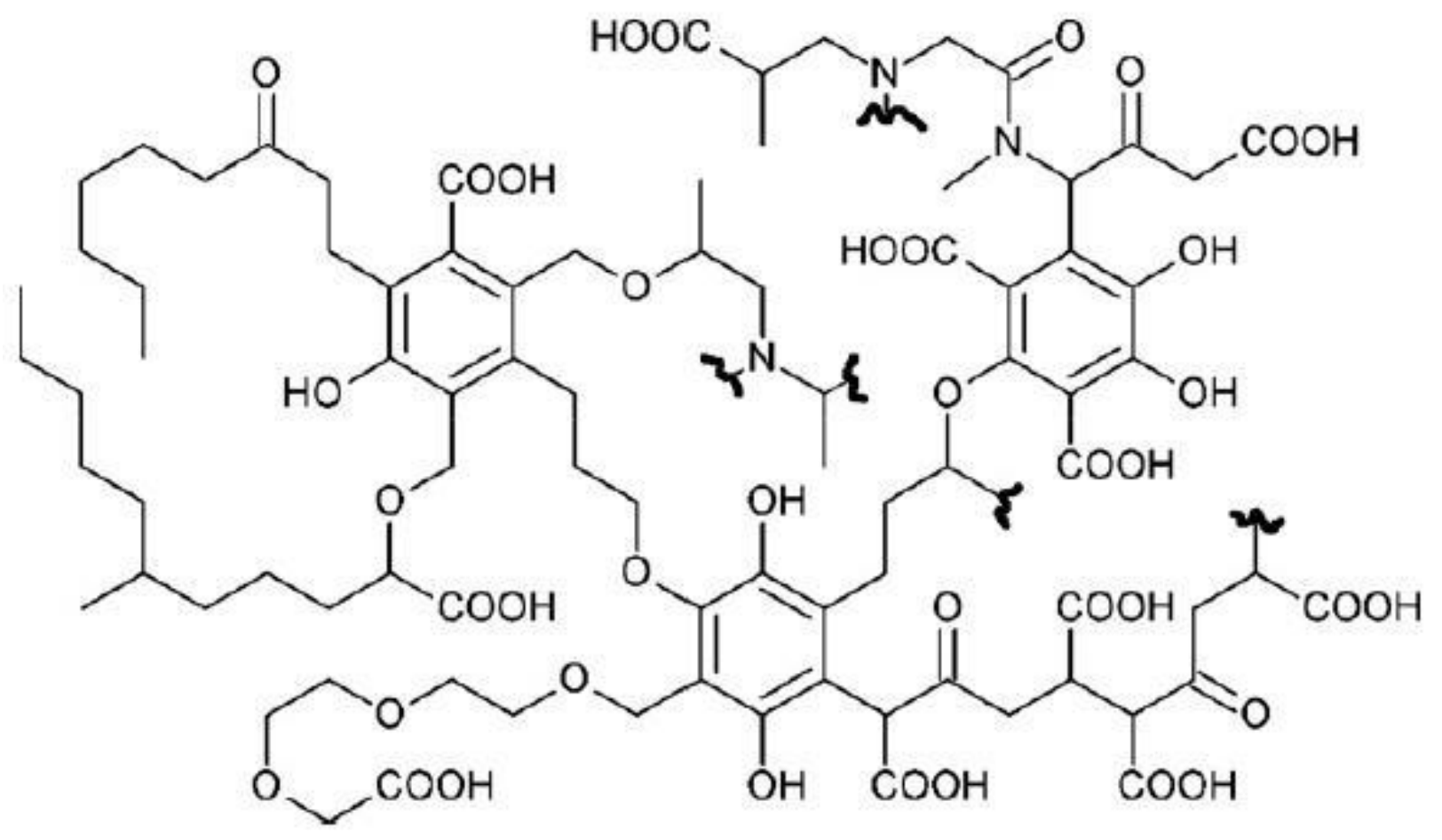

Scheme 1 Virtual molecular fragments of BBS [9].

BBS have been found [18] to possess enhanced adsorption capacity for hydrophilic polar water pollutants. As already discussed, they have the potential to interact with polar pollutants due to the presence of organic functional groups like carboxylate and phenolic groups, which are negatively 
charged at neutral $\mathrm{pH}$. Hence there is an electrostatic interaction between the negatively charged BBS moieties and the positively charged surface materials $[19,20]$.

Due to the acidic nature, it can be employed for the surface functionalization of specific inorganic oxides to produce new hybrid materials. The surface character (surface charge) of new hybrid materials has been modified. Green methods have been used for the development of these materials to be used for the removal of pollutants from waste water.

\section{Application of Bbs in Surface Functionalization}

Several authors have reported the application of BBS materials in their work. This work focuses on the preparation of hybrid materials by surface functionalization of alumina for the application in waste water treatment. Alumina, possessing a large surface area, has been used as a surface for immobilization of molecules. They are stable and have a positive surface charge in a broad $\mathrm{pH}$ range. Razieh Sadraei and her colleagues, for the first time, proposed an easy synthetic route of hybrid materials (Alumina-BBS) by simple surface functionalization. They assumed the presence of a simple electrostatic interaction between alumina from boehmite (Alumina Boeh) and used as a support for the immobilization of BBS and BBS substrates. The alumina and the BBS substrates carry positive and negative charges, respectively. The optimum amount of BBS for the functionalization of alumina surfaces has already been studied. According to previous reports, $0.4 \mathrm{~g}$ of BBS was found to be the best performer for the functionalization of alumina from boehmite and dawsonite precursors for the preparation of novel hybrid adsorbents. The experiments were conducted using $0.1,0.2$, and $0.4 \mathrm{~g}$ of BBS. These hybrid materials were tested for the removal of polar pollutants from waste water. Before testing them, the hybrid materials were completely characterized by means of X-Ray Diffraction (XRD) to evaluate their crystal structure after functionalization. The results of XRD showed that the crystal structure of support materials does not change due to surface functionalization. The samples were analyzed by Fourier transform infrared spectroscopy (FTIR) for evaluating the presence of BBS on the hybrid materials. The stability of the hybrid materials and the amount of BBS immobilized on the alumina supports was measured by thermogravimetric analysis (TGA). The surface charge of materials before and after functionalization was measured by means of Zeta Potential (ZP). The results indicate that BBS has an effect on the surface charge of the support particles and consequently helps in choosing a compatible substrate interaction. It also indicates that after functionalization, the surface charge of alumina gets modified. As can be seen in Figure 2, the surface alumina is mostly positively charged in a broad range of $\mathrm{pH}$. This helps in forging an electrostatic interaction between the positively charged solid surface and the negatively charged substrates. In fact, the BBS molecules are negatively charged at neutral $\mathrm{pH}$ because of the dissociated $\mathrm{COOH}$ and phenolic groups. Therefore, the interaction between a positive alumina surface and negatively charged BBS substrates occurs readily. The isoelectric point (IEP) shifted to lower pH upon functionalizing BBS, indicating the loading of BBS on the surface of alumina. 


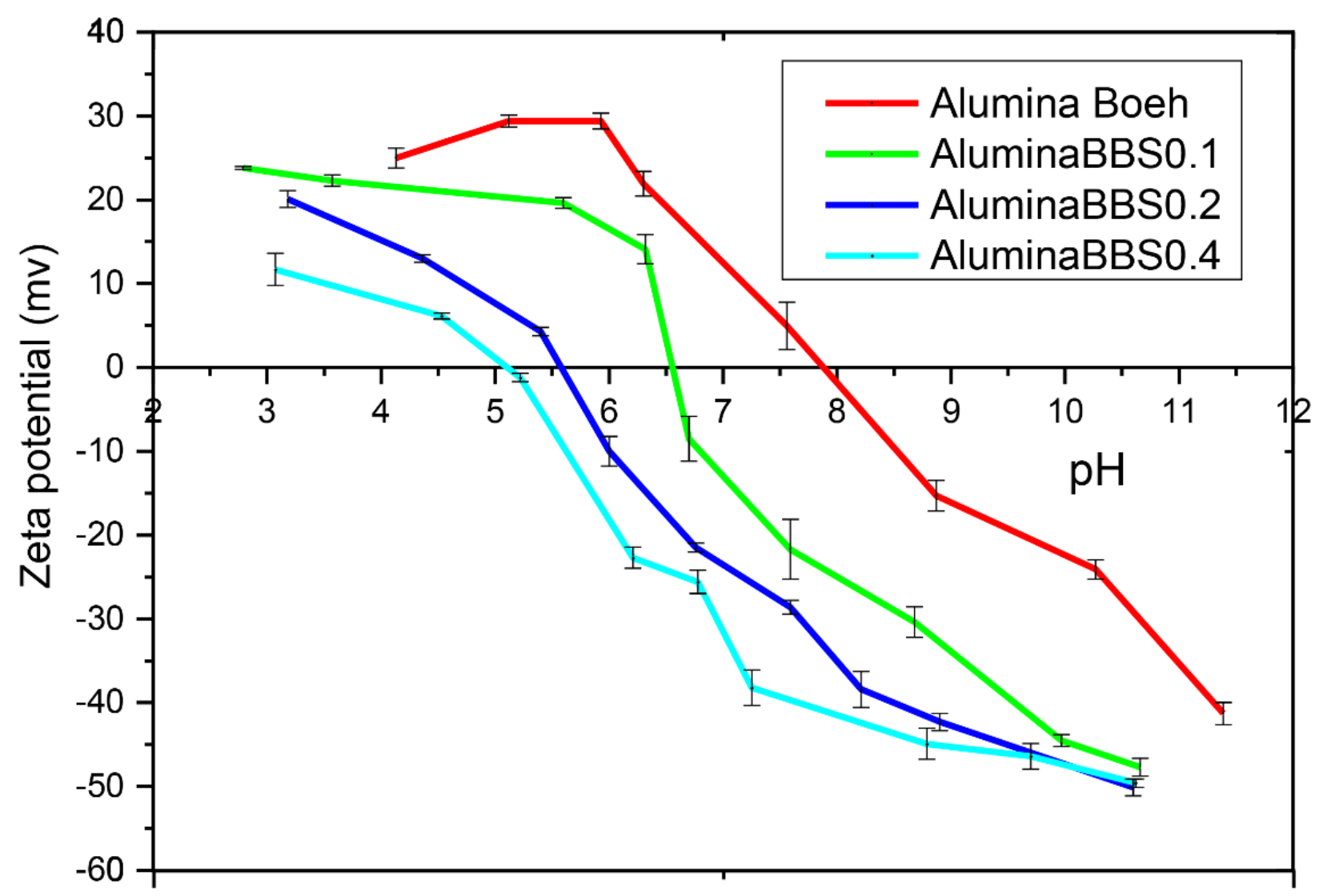

Figure 2 Zeta potential trends of gamma-Alumina (before functionalization), AluminaBBS0.1, Aalumina-BBSO.2 and Aalumin-BBSO.4 (after functionalization by BBS in various ratio) as a function of $\mathrm{pH}[19]$.

The adsorption efficiency of BBS coated hybrid materials toward cationic species under various adsorbate/adsorbent ratio was studied. Crystal Violet (CV) was selected as a model pollutant for comparing the performance of the hybrid materials with those of others reported in the literature. CV is compatible with anionic adsorbents. According to the results of ZP experiments, Alumina BBSO.4, with a highly negatively charged surface, could be applied for the adsorption of positively charged molecules like the CV dye. Figure 3 shows the efficiency of the samples as adsorbents for CV against time. From the graph, it is evident that the percentage of removal of CV by functionalized alumina is significantly different from that of unfunctionalized alumina. This indicates that the surface of alumina after functionalization has been selectively modified. BBS moieties were immobilized in the pores of the alumina surface. These played an important role in the surface of alumina oxides by modifying the positively charged surface of the support to a negatively charged surface. Alumina, by itself is not capable of adsorbing $\mathrm{CV}$ at $\mathrm{pH}$ 7. The adsorption of $\mathrm{CV}$ by the hybrid adsorbents occurs within a short time span (in about $10 \mathrm{~min}$ ), which is interesting from many perspectives. 


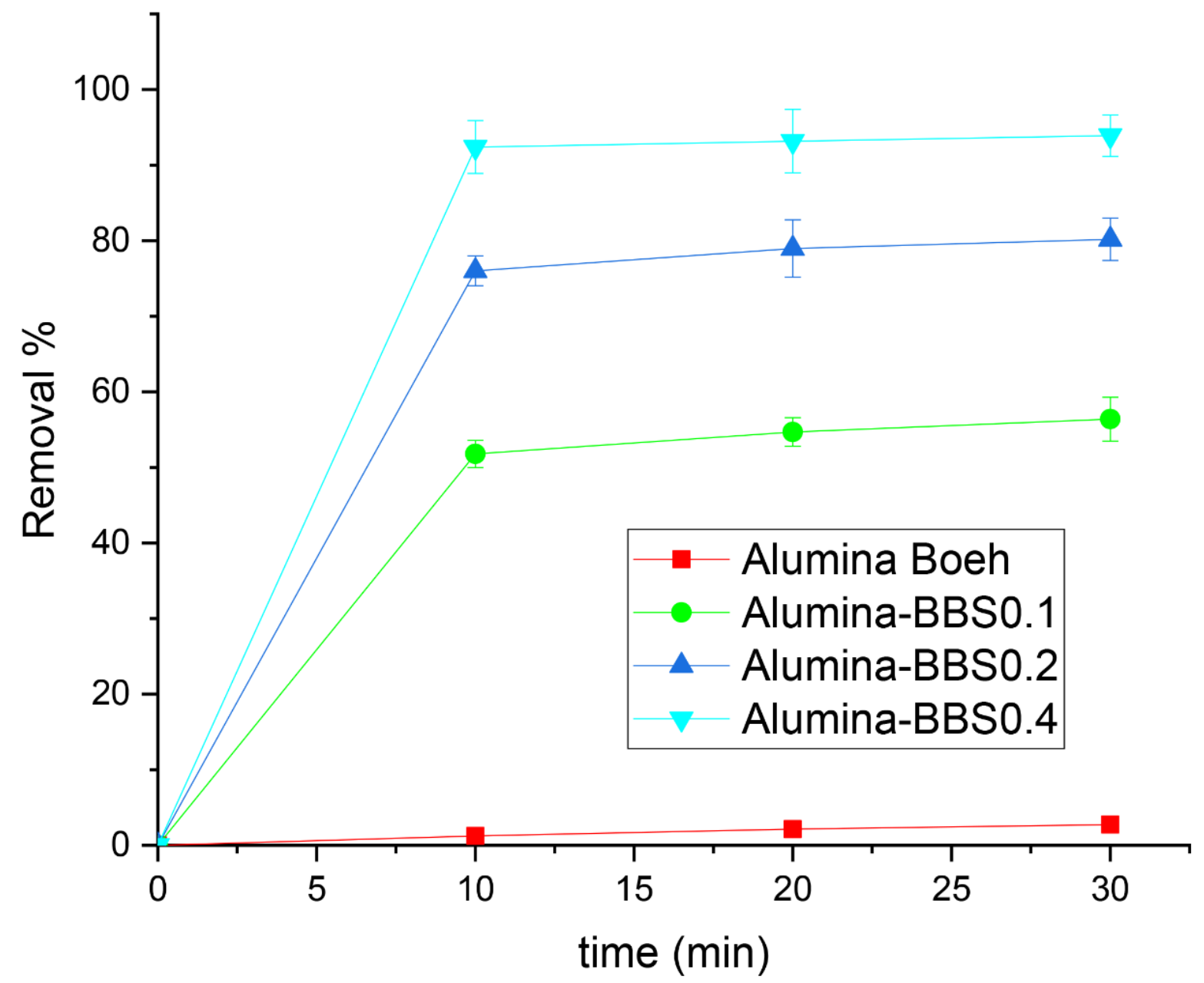

Figure 3 Percentage of dye removal (from $10 \mathrm{ppm}$ ) by $20 \mathrm{mg}$ of alumina before the functionalization (red square), Alumina-BBSO.1 (green triangles), Alumina-BBSO.2 (dark blue circles) and Alumina-BBSO.4 (light blue diamonds) in $10 \mathrm{~mL}$ [19].

Sadraei worked on developing an easy synthetic strategy for alumina from dawsonite (Alumina Daw) in different phases. She reported the synthesis of a room temperature hybrid material by using gammaalumina dawsonite (AACH) functionalized by Bio-Based Substances (BBS). She showed that these new hybrid materials can be used for the efficient adsorption of positively charge pollutants from the waste water. The procedure of synthesis and preparation of the hybrid materials involves simple electrostatic interaction occurring between positively charged alumina support and negatively charged BBS substrates. This is thus a green procedure. The new hybrid materials were characterized using similar protocols. The efficiency of this adsorbent for adsorbing negatively charged contaminants in the waste water obtained from ZP experiments is illustrated in Figure 4 [21].

Figure 4 Shows the ZP results of Alumina Daw (before functionalization) and Alumina BBS0.4 (support after functionalization). As is evident, Alumina Daw has a positive surface charge in a wide range of $\mathrm{pH}$. This positive surface charge favors electrostatic interaction with negatively charged materials. The IEP for Alumina Daw sample is about 9. This indicates that Alumina Daw is positively 
charged at $\mathrm{pH}<9$, and is partially negatively charged at $\mathrm{pH}>9$. Upon functionalization of BBS, the IEP shifts to a lower $\mathrm{pH}$ significantly and decreased to $\mathrm{pH} 5$. As already discussed, the total surface charge of hybrid material reduced remarkably due to the presence of hydroxyl and carboxyl groups in BBS [21]. Compared to previous reports, the decrease was significant. The nature of the alumina precursor can explain such a drastic decrease in $\mathrm{pH}$ value (in this case, dawsonite). The $\mathrm{N}_{2}$ adsorption and desorption analysis indicated that in the present case, greater amounts of BBS molecules were located on the support. Consequently, the surface-functionalized alumina support from dawsonite contains more anionic groups as compared to alumina from the boehmite precursor.

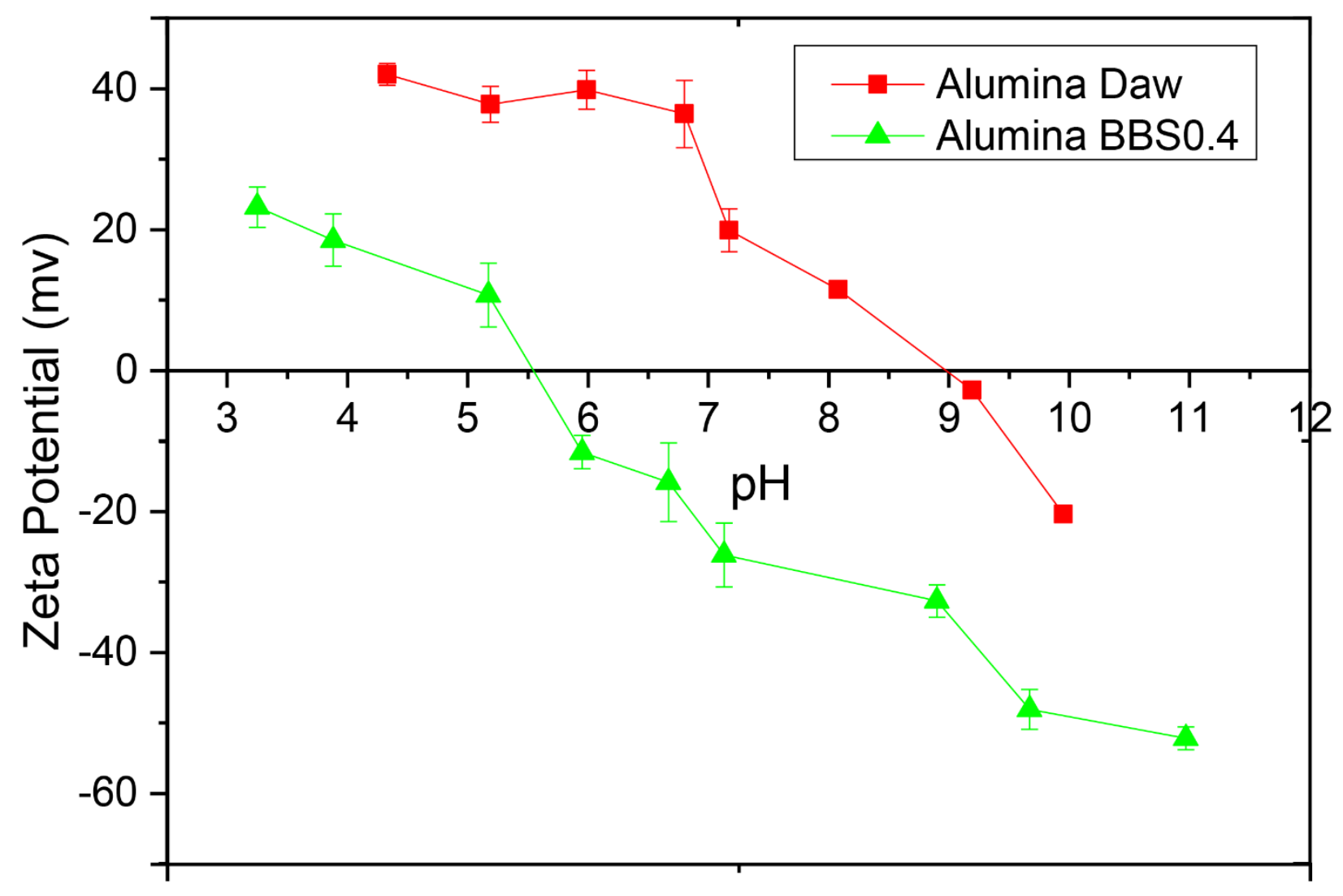

Figure 4 Zeta potential trends of Alumina Boeh (red squares) before the functionalization, Alumina-BBSO.4 (green diamonds) after BBS functionalization at $\mathrm{pH} 7$, as a function of $\mathrm{pH}$ [21].

The curves of the adsorption of the $\mathrm{CV}$ dye on Alumina Daw and hybrid materials are presented in Figure 5. The experimental protocols are reported in the literature [21]. The $\mathrm{pH}$ of all the adsorption experiments was adjusted to $\mathrm{pH} 7$. The adsorption equilibrium was reached in less than $30 \mathrm{~min}$. Of CV, $99 \%$ was removed by hybrid materials, while only $20 \%$ of the dye was removed by alumina support. Due to the positive charge of CV dye and the surface charges of hybrid adsorbing materials, a high electrostatic interaction occurs between the surface of the adsorbents and the CV dye [21]. 


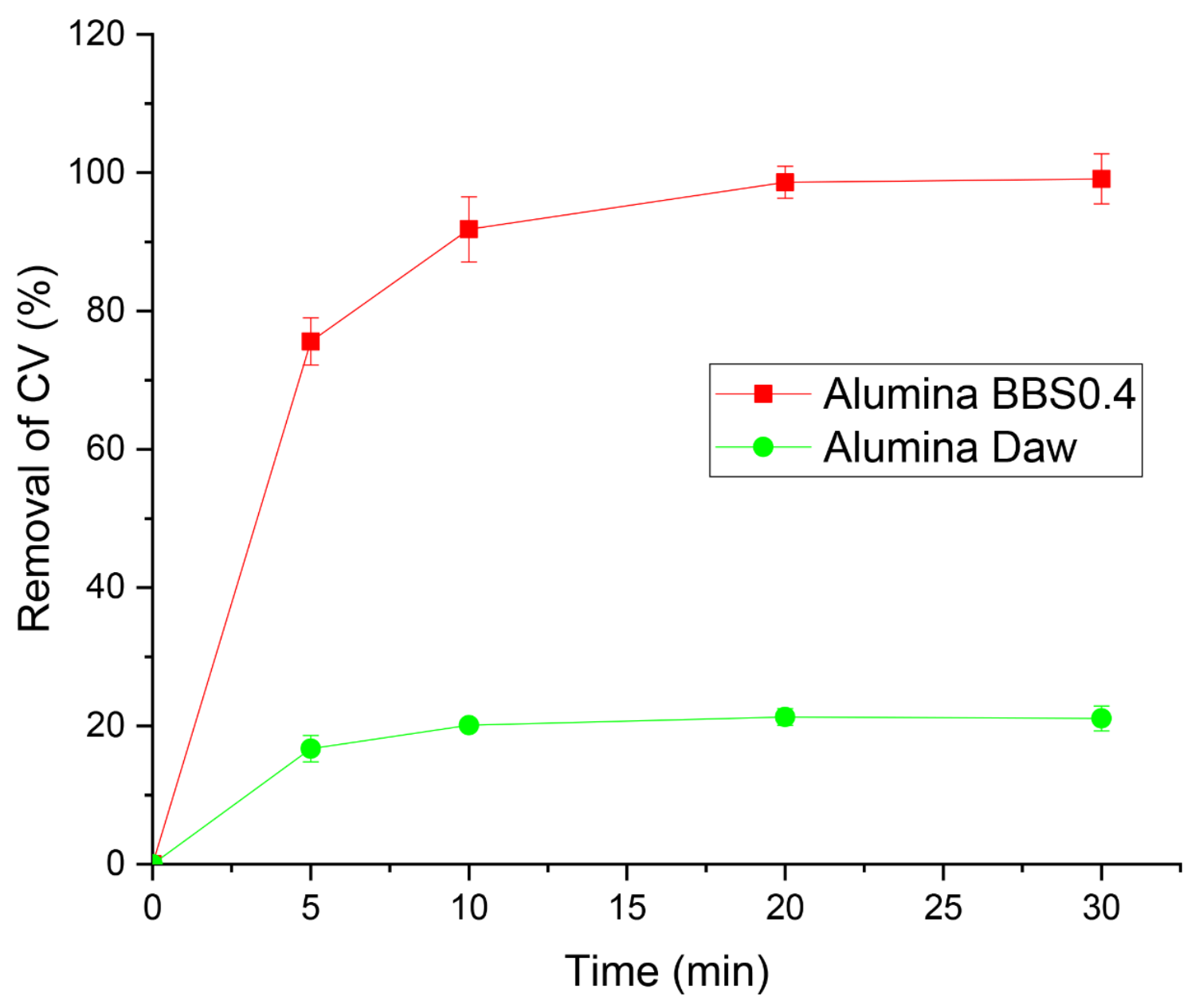

Figure 5 Percentage of CV removal (from $10 \mathrm{ppm}$ ) by $5 \mathrm{mg}$ of Alumina-BBSO.4 (squares) and Alumina Daw (circles) in a volume of $10 \mathrm{~mL}$ at $15^{\circ} \mathrm{C}$ [21].

\section{Discussion}

The application of bio-based substances, extracted from compost bio-waste, in the surface functionalization of alumina oxides has been studied in this work. Two different precursors of alumina (boehmite and dawsonite) were considered for the experiments. We assumed that these will show different behavior during BBS functionalization due to their difference in shape and other properties. In both cases, the interaction between BBS and alumina was assumed to be electrostatic in nature due to the presence of positive charge on the surface of alumina and negative charge on BBS. Alumina from both boehmite and dawsonite was successfully surface functionalized following green chemistry [19]. No chemical reagent or organic solvent was used during functionalization. ZP experiments were conducted for the support materials before and after functionalization to prove surface modification in both kinds of alumina. Hybrid materials were compared with unmodified alumina to gauge their efficiency in removing positively charged polar pollutants from wastewater. The results were compared in order to choose the more efficient hybrid adsorbent having a higher adsorption capacity, which can be used for industrial applications. It was found that the alumina from boehmite and dawsonite were 
inefficient adsorbents for water treatment. However, after BBS surface functionalization, they showed significant adsorption efficiency for the positively charged CV dye.

The adsorption efficiency was found to be remarkably high in the case of Alumina Dawsonite functionalized with BBS, indicating that it is better support for BBS molecules. The two major advantages of using alumina-BBSO.4 as an adsorbent are the easy and green methods followed for synthesis and the cost efficiency. Unlike other adsorbents, the preparation of these hybrid adsorbents does not require any pretreatment or energy consumption. The extraction of BBS from compost biowaste does not involve extra cost. Thus, from these perspectives, the green hybrid materials based on alumina from dawsonite can be applied in wastewater treatment. It can be a good competition to other hybrid adsorbents and may find significant application in industries.

\section{Author Contributions}

Razieh Sadraei did all work.

\section{Competing Interests}

The author has declared that no competing interests exist.

\section{References}

1. Nisticò R, Barrasso M, CarrilloLeRoux GA, Seckler MM, Sousa W, Malandrino M, et al. Biopolymers from composted biowaste as stabilizers for the synthesis of spherical and homogeneously sized silver nanoparticles for textile applications on natural fibers. ChemPhysChem. 2015; 16: 39023909. doi:10.1002/cphc.201500721.

2. Franzoso F, Nisticò R, Cesano F, Corazzari I, Turci F, Scarano D, et al. Biowaste-derived substances as a tool for obtaining magnet-sensitive materials for environmental applications in wastewater treatments. Chem Eng J. 2017; 310, 307-316. doi:10.1016/j.cej.2016.10.120.

3. Tummino ML, Testa ML, Malandrino M, Gamberini R, Prevot AB, Magnacca G, et al. Green wastederived substances immobilized on sba-15 silica: Surface properties, adsorbing and photosensitizing activities towards organic and inorganic substrates. Nanomaterials. 2019; 9: 162. doi:10.3390/NANO9020162.

4. Bianco Prevot A, Baino F, Fabbri D, Franzoso F, Magnacca G, Nisticò R, et al. Urban biowastederived sensitizing materials for caffeine photodegradation. Environ Sci Pollut Res. 2017; 24 : 12599-12607. doi:10.1007/s11356-016-7763-1.

5. Avetta P, Bella F, Bianco Prevot A, Laurenti E, Montoneri E, Arques A, et al. Waste cleaning waste: Photodegradation of monochlorophenols in the presence of waste-derived photosensitizer. ACS Sustain Chem Eng. 2013; 1: 1545-1550. doi:10.1021/sc400294z.

6. Magnacca G, Neves Dos Santos F, Sadraei R. Bio-based substances from compost as reactant and active phase for selective capture of cationic pollutants from waste water. Front Chem. 2020. doi: 10.3389/fchem.2020.00550. 
7. Montoneri E, Boffa V, Savarino P, Perrone D, Ghezzo M, Montoneri C, et al. Acid soluble bio-organic substances isolated from urban bio-waste. Chemical composition and properties of products. Waste Manag. 2017; 31: 10-17. doi:10.1016/j.wasman.2010.08.029.

8. Montoneri E, Boffa V, Savarino P, Perrone DG, Musso G, Mendichi R, et al. Biosurfactants from urban green waste. ChemSusChem. 2019; 2: 239-247. doi:10.1002/cssc.200800199.

9. Magnacca G, Laurenti E, Vigna E, Franzoso F, Tomasso L, Montoneri E, et al. Refuse derived bioorganics and immobilized soybean peroxidase for green chemical technology. Process Biochem. 2012; 47: 2025-2031. doi:10.1016/j.procbio.2012.07.021.

10. Sadraei R, Murphy RS, Laurenti E, Magnacca G. Characterization methodology to evaluate the activity of supported soybean peroxidase. Ind Eng Chem Res. 2019; 58: 19082-19089. doi:10.1021/acs.iecr.9b03495.

11. Razieh S. Protein adsorption from aqueous solution by supports. Bioinform Proteom Open Acc J. 2017; 1: 000108.

12. Guzmán E, Liggieri L, Santini E, Ferrari M, Ravera F. DPPC-DOPC Langmuir monolayers modified by hydrophilic silica nanoparticles: Phase behaviour, structure and rheology. Colloids Surfaces $A$ Physicochem Eng Asp. 2012; 413: 174-183. doi:10.1016/j.colsurfa.2011.12.059.

13. Montoneri E, Mainero D, Boffa V, Perrone DG, Montoneri C. Biochemenergy: A project to turn an urban wastes treatment plant into biorefinery for the production of energy, chemicals and consumer's products with friendly environmental impact. Int J Glob Environ. 2011; 11: 170-196. doi:10.1504/IJGENVI.2011.043528.

14. Zhao XS, Bao XY, Guo W, Lee FY. Immobilizing catalysts on porous materials. Mater Today. 2006; 9: 32-39. doi:10.1016/S1369-7021(06)71388-8.

15. Shoukat S, Bhatti HN, Iqbal M, Noreen S. Mango stone biocomposite preparation and application for crystal violet adsorption: A mechanistic study. Micropor Mesopor Mat. 2017; 239: 180-189. doi:10.1016/j.micromeso.2016.10.004.

16. Klučáková M, Kalina M. Composition, particle size, charge, and colloidal stability of pH-fractionated humic acids. J Soils Sediments. 2015; 15: 1900-1908. doi:10.1007/s11368-015-1142-2.

17. Hu WG, Mao J, Xing B, Schmidt-Rohr K. Poly(methylene) crystallites in humic substances detected by nuclear magnetic resonance. Environ Sci Technol. 2000; 34: 530-534. doi:10.1021/es990506I.

18. Magnacca G, Allera A, Montoneri E, Celi L, Benito DE, Gagliardi LG, et al. Novel magnetite nanoparticles coated with waste-sourced biobased substances as sustainable and renewable adsorbing materials. ACS Sustain Chem Eng. 2014; 2: 1518-1524. doi:10.1021/sc500213j.

19. Sadraei R, Paganini MC, Calza P, Magnacca G. An easy synthesis for preparing bio-based hybrid adsorbent useful for fast adsorption of polar pollutants. Nanomaterials. 2019; 9: 731. doi:10.3390/nano9050731.

20. Sadraei R. A simple method for preparation of Nano-sized ZnO. Res Rev J Chem. 2016; 5: 45-49. Available at: https://www.researchgate.net/publication/308953404.

21. Sadraei R. Fast, green and easy adsorption of dye and emerging contaminants by functionalized $\gamma$ AACH. J Environ Chem Eng. 2019; 8: 103616. doi:10.1016/j.jece.2019.103616. 


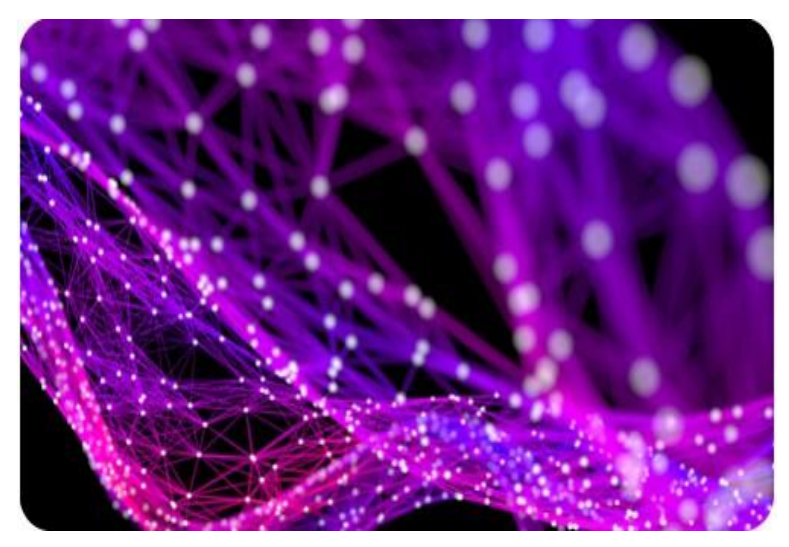

Enjoy Recent Progress in Materials by:

1. Submitting a manuscript

2. Joining in volunteer reviewer bank

3. Joining Editorial Board

4. Guest editing a special issue

For more details, please visit:

http://www.lidsen.com/journals/rpm 